Meta

Journal des tradlucteurs

Translators' Journal

\title{
Des tréteaux au petit écran
}

\section{Robert Dubuc}

Volume 11, numéro 2, juin 1966

URI : https://id.erudit.org/iderudit/010467ar

DOI : https://doi.org/10.7202/010467ar

Aller au sommaire du numéro

Éditeur(s)

Les Presses de l'Université de Montréal

ISSN

0026-0452 (imprimé)

1492-1421 (numérique)

Découvrir la revue

Citer ce document

Dubuc, R. (1966). Des tréteaux au petit écran. Meta, 11(2), 65-67.

https://doi.org/10.7202/010467ar

Ce document est protégé par la loi sur le droit d'auteur. L'utilisation des services d'Érudit (y compris la reproduction) est assujettie à sa politique d'utilisation que vous pouvez consulter en ligne.

https://apropos.erudit.org/fr/usagers/politique-dutilisation/
Cet article est diffusé et préservé par Érudit.

Érudit est un consortium interuniversitaire sans but lucratif composé de l’Université de Montréal, l'Université Laval et l'Université du Québec à Montréal. Il a pour mission la promotion et la valorisation de la recherche. https://www.erudit.org/fr/ 


\section{DES TRÉTEAUX AU PETIT ÉCRAN}

$\mathrm{Au}$ palmarès des monstres créés par le jargon de la radiotélévision, il faudrait bien réserver une place de choix à «continuité ». Comme chacun le sait, ce terme cher aux Marie-Chantal de l'éther désigne les romans télévisés qui valent à la télévision canadienne-française ses cotes d'écoute les plus mirobolantes. La suite des épisodes qu'on étiquette ainsi peut certes à l'occasion paraître interminable, mais ce n'est pas suffisant, à ce qu'il semble, pour accréditer ce néologisme douteux sans autre forme de procès.

Continuité, en français, est un terme abstrait qui désigne la liaison non interrompue des parties, la reproduction prolongée d'une chose: la continuité d'un son. On conçoit mal - malgré toute la continuité qu'il puisse y avoir dans un roman qui dure depuis trente ans - que Les Belles Histoires de Grignon puissent porter le nom de continuité comme genre littéraire. D'où nous vient cet emploi incongru? Nous sommes, selon toute apparence, en présence de ce qu'on pourrait appeler un anglicisme d'ignorance ou de snobisme.

Le mot anglais continuity désigne le découpage d'un texte, c'est-à-dire son adaptation à la télévision: répartition par scène, notations scéniques, mouvements de caméras, etc. Par extension, le mot en est venu à désigner le texte lui-même ${ }^{1}$. Mais là s'arrête son évolution. Ce mot anglais n'a rien à voir avec nos « continuités » qui sont des serials en anglais. Cependant le mot a plu à quelque vedette plus soucieuse de nouveauté que de précision en matière de langage et il a fait tache d'huile. Sa consonance française a facilité sa migration. Les contes des mille et une nuits de l'ère atomique portent donc le nom de continuités. Cet abus est d'autant plus répréhensible que nous ne manquons pas de termes reçus en français pour désigner cette réalité.

Bien avant la venue des ondes porteuses de sons et d'images, nos grandmères trouvaient le moyen de s'émouvoir en suivant les aventures de leurs héros favoris dans le feuilleton de leur journal. Les femmes de notre époque retrouvent aujourd'hui sur les ondes ce compagnon de leurs loisirs; pourquoi faudrait-il s'ingénier à lui trouver un nom nouveau quand feuilleton comporte déjà la notion d'un récit suivi, donné par tranche? L'usage universel a déjà répondu à cette question: «La Divine Lady, premier feuilleton radiophonique, paraîtra dans les Nouvelles littéraires ${ }^{2}{ }$; « Le nouveau feuilleton Tintin et Milou arrivent ... comportera 13 émissions de quatorze minutes ${ }^{3}$.

\footnotetext{
1. Académie canadienne-françaíse, Bulletin de linguistique, $\mathrm{n}^{\circ} 23$.

2. Erest, Nouvelles littéraires, 9-1-58.

3. T'élémagazine, $\mathrm{n}^{\circ} 110,1957$. 
Feuilleton est l'équivalent le plus juste du serial anglais, mais il y a également d'autres termes qui valent d'être retenus. Il convient de mentionner par exemple roman-fleuve, passé lui aussi de la littérature écrite à la littérature orale. «Dans le déroulement même du roman-fleuve ... il y a dans l'ordre des études, dans la succession des épisodes ... quelque chose de statique ${ }^{4}$.»

Jamais en reste de synonymes, l'américain a étiqueté ses romans radiophoniques en décochant une pointe d'humour aux commanditaires de ces émissions: soap operas. C'est une amusante trouvaille typiquement anglo-saxonne, qu'on essaierait en vain de rendre dans toute sa verdeur. Le calque roman-savon n'est pas très heureux. Le français répugne à cet alliage de mots brutalement concret.

À Radio-Canada, place s'est faite aux vocables radioroman et téléroman. Ces mots offrent l'avantage de leur commodité. Mais leurs titres de noblesse ne sont pas encore tout à fait acquis. Toutefois, ils font partie de familles linguistiques dont le domaine tend à s'accroître constamment: téléspectateur, téléthéâtre, téléaste, télécinéma semblent aujourd'hui des termes accrédités, sinon par l'Académie, du moins par la majorité des bons journalistes et chroniqueurs de télévision de part et d'autre de l'Atlantique. Il en est de même de certains composés de radio: radiojournal, radiotaxi. On peut donc légitimement les employer à moins d'avis contraire de l'autorité compétente! Vivent donc radioroman et téléroman !

Mais avec ces deux termes, nous ne couvrons qu'une toute petite aire du théâtre télévisé. À la recherche d'un terme générique pour désigner toutes les émissions qui tiennent du théâtre, les Français ont opté pour dramatique, contraction de l'expression émission dramatique. C'est le même procédé qui nous a d'ailleurs donné automobile, contraction de vêhicule automobile. Voici quelques exemples de cet emploi: «X projette de réaliser de courtes dramatiques de trente minutes chacune ${ }^{5} » ;$ 《Sur le plan des dramatiques, on se rend compte que la TV n'a pas trouvé sa grammaire propre ${ }^{6}$. André Brincourt $^{7}$ préfère téléthéâtre à dramatique. Téléthéâtre sert depuis longtemps à Radio-Canada comme titre d'une série prestigieuse. Son passage dans la langue du métier s'en trouverait d'autant facilité chez nous. Téléthéâtre conviendrait beaucoup mieux comme terme générique que dramatique ${ }^{8}$. S'il en est encore temps, il faudrait en pousser l'utilisation.

Pour compléter cet inventaire des désignations des émissions de télévision ou de radio, mentionnons deux termes fort utiles et déjà en usage: série et cycle.

La série désigne un groupe d'émissions présentées selon un ordre prétabli, à intervalles réguliers et sous un même titre. Ce terme équivaut à l'anglais series. La série se distingue du feuilleton ou serial d'abord parce qu'elle n'est pas nécessairement dramatique et aussi parce qu'ordinairement chaque émission d'une série forme un tout complet en lui-même.

4. R. Boyer, Cahiers d'étude de la radio-télévision, no 13, p. 4.

5. Télémagazine, $\mathrm{n}^{\circ} 153,1958$.

6. H. Decoin, Télé $58, \mathrm{n}^{\circ} 735,1958$.

7. La Télévision et ses promesses. Paris, la Table ronde, 1960, p. 134.

8. MM. Alain Guillermou et Joseph Hanse se sont faits les avocats de téléthéâtre. Cf. Vie et langage, $\mathrm{n}^{\circ} 130$, p. 22. 
Quant à cycle, il s'applique à une sous-série d'émissions didactiques. Pour désigner un ensemble d'émissions qui couvre un sujet donné, on trouve fréquemment le mot cycle. "Quant à l'illustration du développement de certaines formes musicales, citons: les cycles sur le quatuor pour archets au XVIII siècle ... ${ }^{9} » ;$ " Des savants éminents ont bien voulu prêter leur concours à notre cycle d'émissions Science in Switzerland. ${ }^{10}$ »

Pour résumer, disons que les programmes de radio ou de télévision se composent soit d'émissions isolées, soit de séries (series). Les séries à caractère didactique se subdivisent souvent en cycles. Les séries à caractère dramatique sont le plus souvent désignées sous le nom de dramatiques (radio ou $T V$ dramas). On tend cependant à substituer téléthéâtre à dramatique dans ce sens. Enfin certaines séries dramatiques ont entre leurs divers épisodes une trame commune qui se continue d'une émission à l'autre. Il s'agit alors de feuilletons (serials). Au Canada, on emploie très souvent dans cette acception téléromans ou radioromans, selon le cas.

R. D.

9. Cahiers d'étude de la radio-télévision, nos 3-4, p. 399.

10. Société Suisse de Radiodiffusion, Rapport annuel, 1955. 